\title{
3 Research Square

\section{A new approach for predicting the future position of a moving object: Hurricanes case study}

wided oueslati ( $\square$ widedoueslati@live.fr)

Institut Supérieur de Gestion: Institut Superieur de Gestion

sonia tahri

ecole superieure de commerce de tunis

hela limam

Institut Supérieur de Gestion: Institut Superieur de Gestion

jalel akaichi

University of Bisha

\section{Manuscript}

Keywords: Future location prediction, Data mining, Trajectory data, Hurricane, Mobility patterns

Posted Date: February 5th, 2021

DOl: https://doi.org/10.21203/rs.3.rs-193248/v1

License: (c) (1) This work is licensed under a Creative Commons Attribution 4.0 International License.

Read Full License

Version of Record: A version of this preprint was published at Applied Artificial Intelligence on December 31st, 2021. See the published version at https://doi.org/10.1080/08839514.2021.1998299. 


\section{Abstract}

Nowadays, huge amounts of tracking data related to moving objects are being generated and collected in suitable repositories thanks to GPS devices, RFIDsensors, satellites and wireless communication technologies. Tracked moving objects could be pedestrians, cars, vessels, planes, animals, natural disasters. Those letters generate trajectory data that contain a great deal of knowledge. For this reason, these trajectory data sets need an urgent and an effective analysis process and constitute a rich source for inferring mobility patterns. Predicting the future position of a given moving object is one of the important tasks we can find in the knowledge discovery process. In fact, being able to predict a moving object's future position related to natural phenomena, would allow decision makers to take strategic decisions in order to help the humanity, and prevent or avoid the propagation of natural catastrophes. The aim of this paper is to propose a new approach to predict the future position of a moving object, especially a moving region based on mobility patterns. To achieve this aim, we experiment our approach on a real case study related to hurricanes as moving regions. The proposed approach is composed of three phases. The first phase allows generating object mobility patterns. In the second phase, spatiotempoal mobility rules are extracted from the generated patterns. In the third and last phase, hurricane future position prediction is accomplished by using the extracted rules.

\section{Full Text}

Due to technical limitations, full-text HTML conversion of this manuscript could not be completed. However, the manuscript can be downloaded and accessed as a PDF.

\section{Figures}




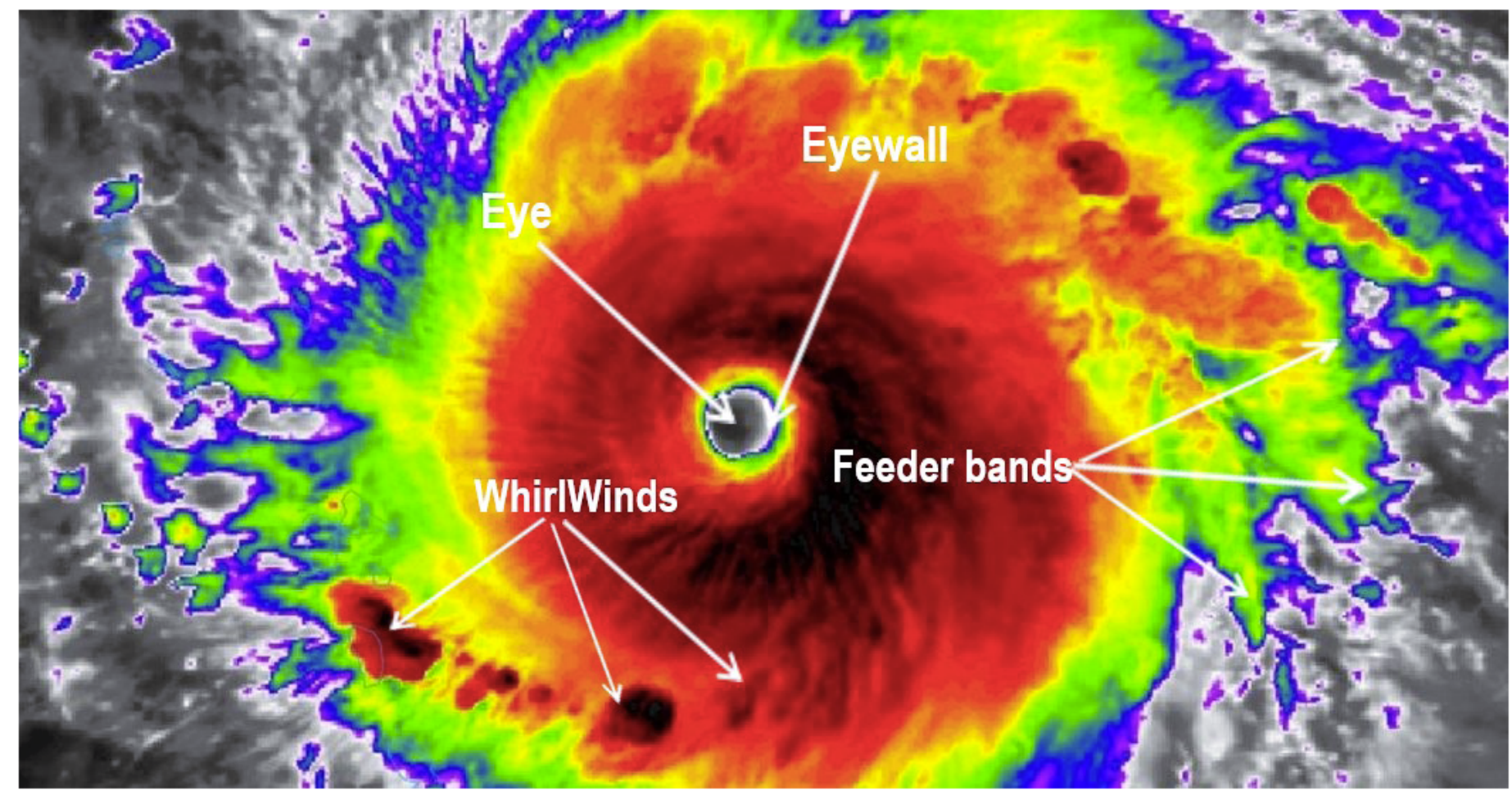

\section{Figure 1}

Hurricane structure by NOAA Center (https://www.nhc.noaa.gov)

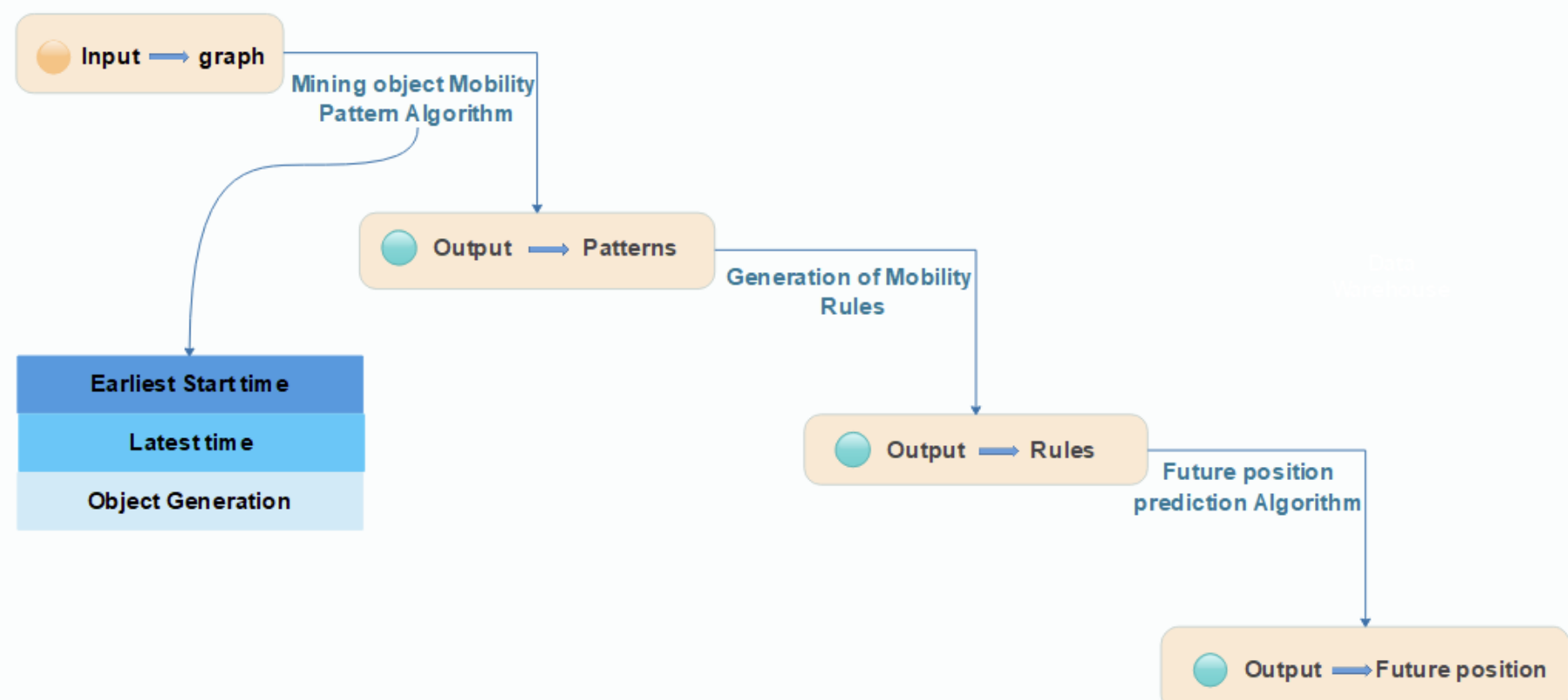

Figure 2

Future position prediction based on spatio-temporel mobility rules architecture 


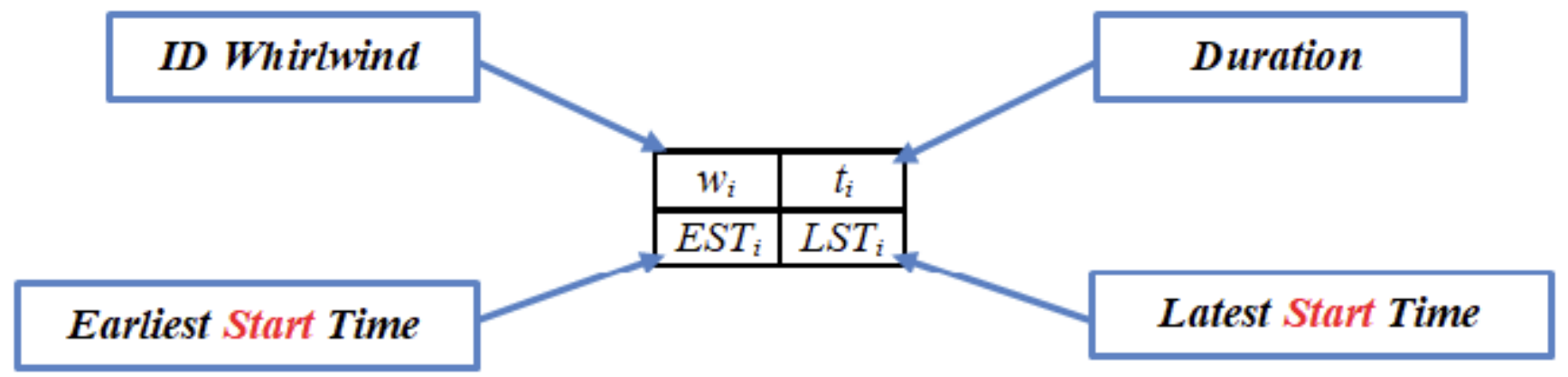

Figure 3

Whirlwind attributes according to MPM method

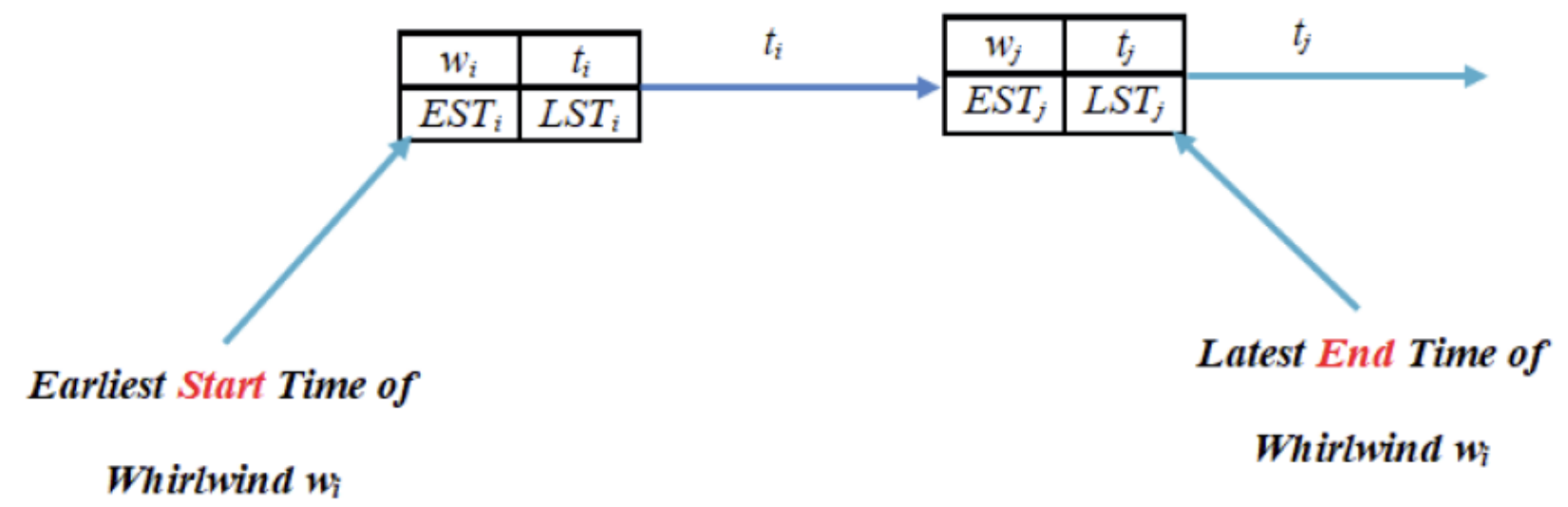

Figure 4

Clarication on MPM reading 


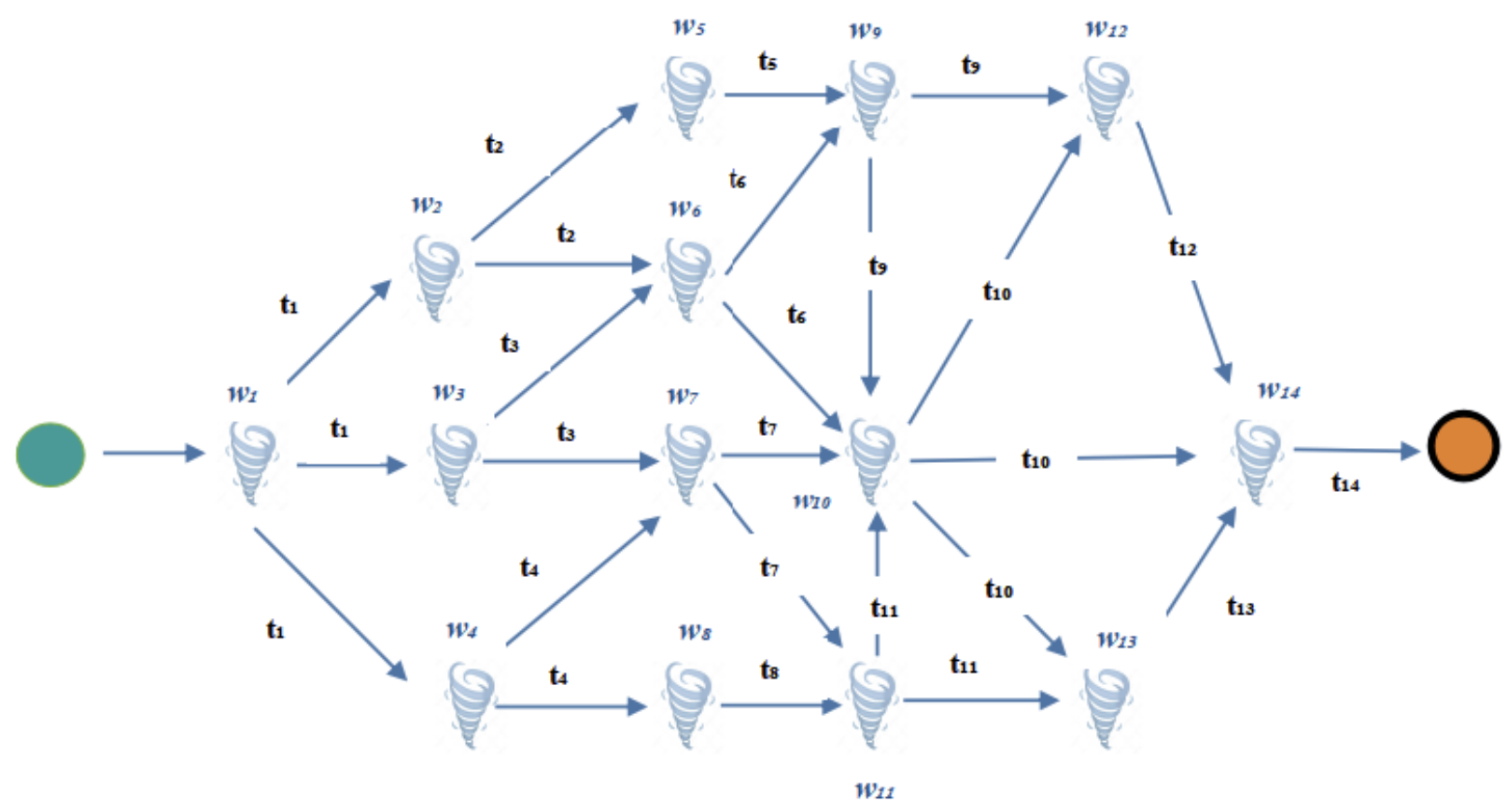

\section{Figure 5}

Corresponding graph $\mathrm{G}$ showing the movement of a set of objects Wk

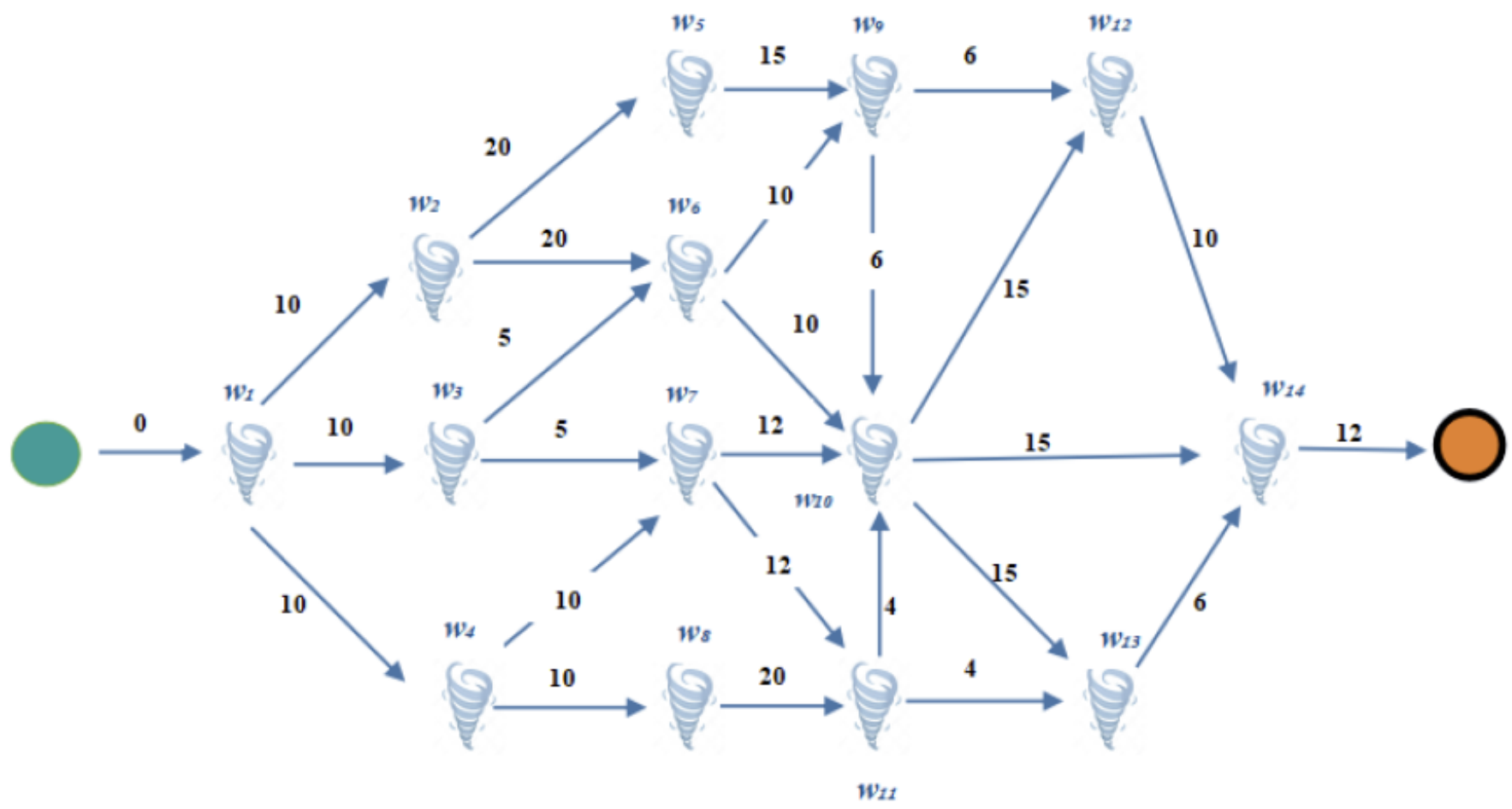

Figure 6 
Earliest Start Time of whirlwind $w$ is :

$\operatorname{Max}(45,40)=45$

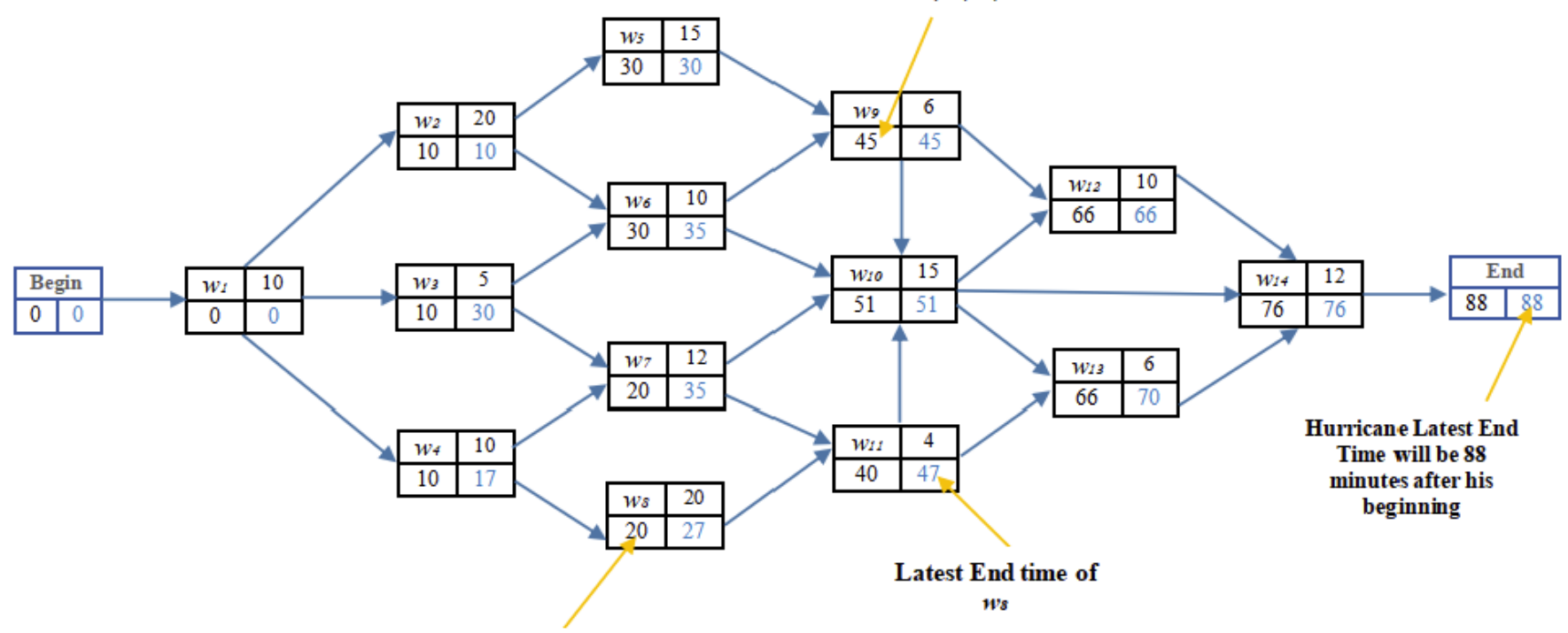

Earliest start time

of $n s$

\section{Figure 7}

Whirlwinds Earliest and Latest times

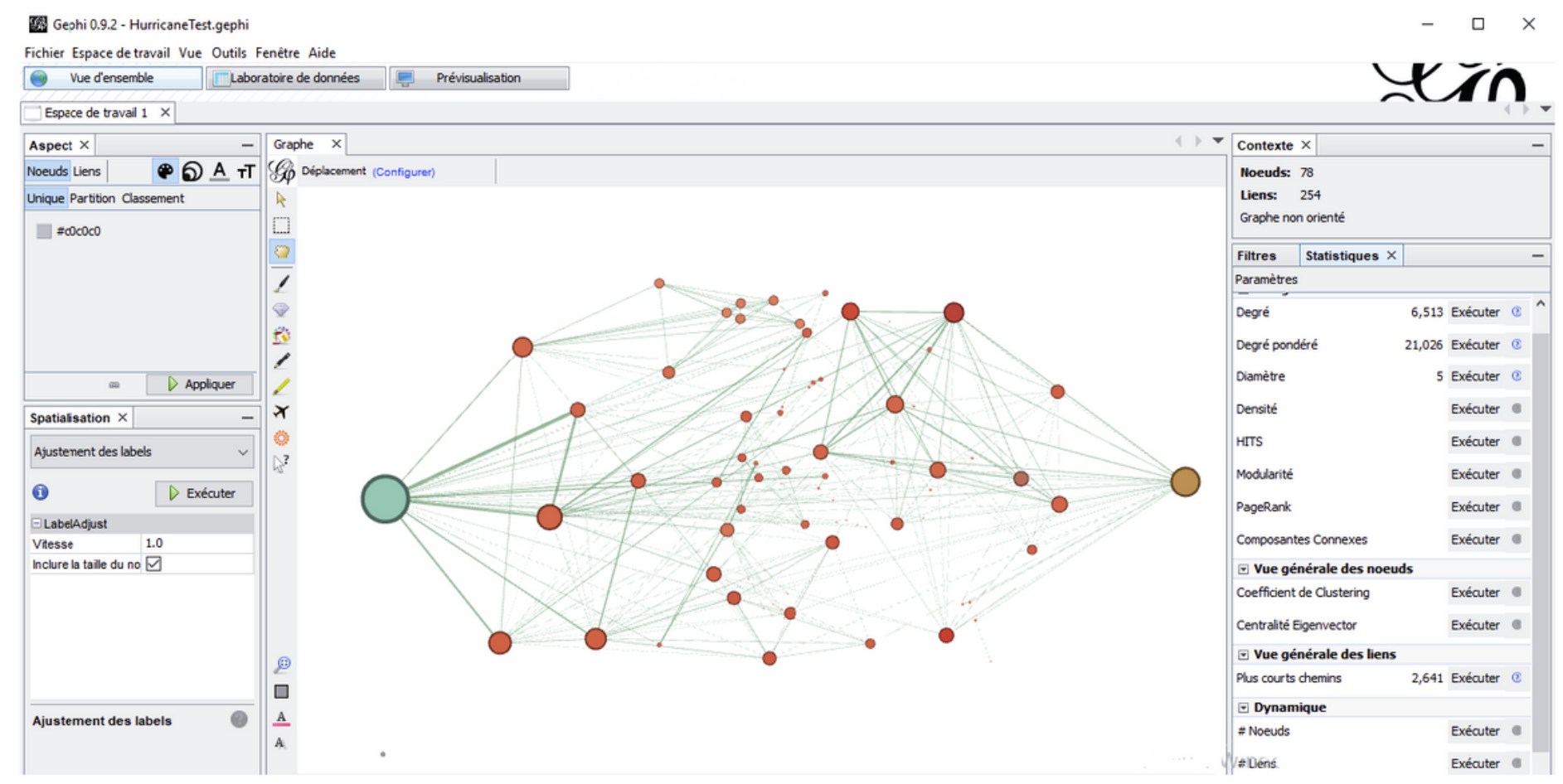

Figure 8

Hurricane graph visualization 


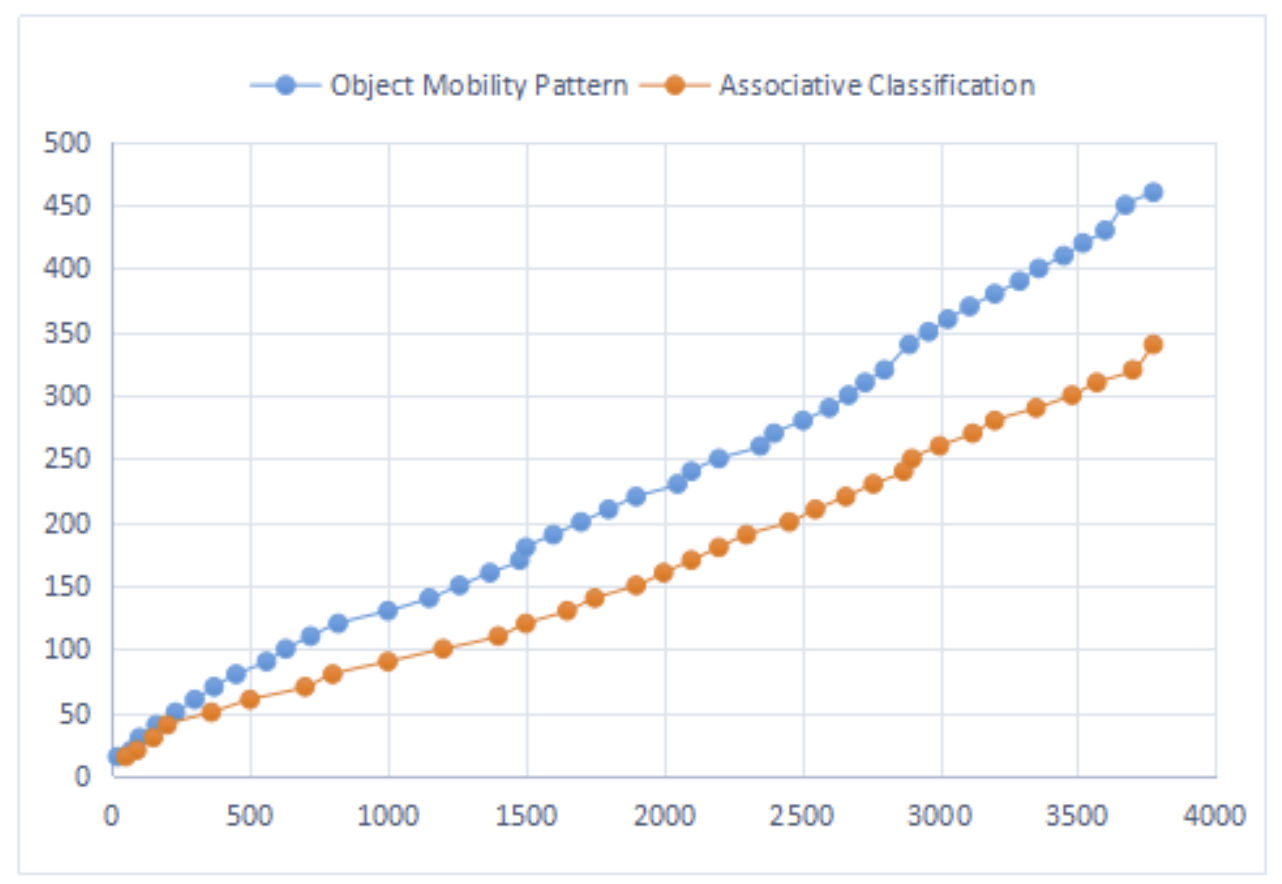

Figure 9

Run time curve 